\title{
Effects of sodium nitroprusside and phenylephrine on coronary dynamics in patients with normal left ventricular function
}

\author{
J. D. STEPHENS, R. P. HAYWARD, D. S. DYMOND, H. EAD, L. ADAMS,
} AND R. A. J. SPURRELL

From the Department of Cardiology, St Bartholomew's Hospital, London

SUMMARY The effects of sodium nitroprusside alone and in combination with phenylephrine were studied at the time of cardiac catheterisation in 10 patients with normal left ventricular function. Nitroprusside was infused to reduce mean arterial pressure in 5 patients with the heart rate free (group 1) and in 5 with the heart rate fixed by atrial pacing (group 2). In group 1 nitroprusside increased heart rate and reduced left ventricular filling pressure and stroke volume. Mean coronary sinus flow increased from $168 \mathrm{ml} / \mathrm{min}$ to $187 \mathrm{ml} / \mathrm{min}$, while mean myocardial oxygen extraction fell from 65 to 58 per cent. Mean myocardial oxygen consumption was unchanged. In group 2 nitroprusside reduced left ventricular filling pressure and stroke volume. Mean coronary sinus flow fell from $154 \mathrm{ml} / \mathrm{min}$ to $121 \mathrm{ml} / \mathrm{min}$ while myocardial oxygen extraction remained unchanged. Mean myocardial oxygen consumption fell from $17 \mathrm{ml} / \mathrm{min}$ to $13 \mathrm{ml} / \mathrm{min}$. Phenylephrine restored mean arterial pressure with associated bradycardia in group 1. Left ventricular filling pressure and stroke volume were restored in both groups. In group 1 phenylephrine produced no further changes in mean coronary sinus flow or myocardial oxygen extraction. In group 2 phenylephrine increased mean coronary sinus flow from $121 \mathrm{ml} / \mathrm{min}$ to $173 \mathrm{ml} / \mathrm{min}$ and increased mean myocardial oxygen consumption from $13 \mathrm{ml} / \mathrm{min}$ to $19 \mathrm{ml} / \mathrm{min}$, myocardial oxygen extraction remaining constant. Nitroprusside is a coronary vasodilator but this action may be counteracted by changes in heart rate or afterload.

Sodium nitroprusside has been shown to produce haemodynamic improvement in patients with congestive cardiac failure after acute myocardial infarction (Franciosa et al., 1972; Chatterjee et al., 1973; Parmley et al., 1974). Though there is evidence that this agent reduces experimental myocardial ischaemia (da Luz et al., 1975), a recent clinical and experimental investigation suggested that nitroprusside might increase myocardial ischaemic injury by reducing coronary perfusion pressure or by producing a 'coronary steal' through a dilating action on coronary resistance vessels (Chiariello et al., 1976). Thus, though nitroprusside may be expected to reduce myocardial oxygen consumption by reducing preload and afterload and thereby reduce ischaemic injury in patients with acute myocardial infarction, it may have the reverse effect if it produces coronary vasodilatation.

This study was performed in an attempt to define the effects of nitroprusside on coronary dynamics under varying haemodynamic conditions.

Received for publication 17 March 1978

\section{Patients and methods}

Ten patients with suspected coronary artery disease were studied at the time of cardiac catheterisation. Informed consent was obtained in all cases. All patients had stable angina pectoris as their presenting symptom. There were 9 men and 1 woman aged between 39 and 63 years (Table 1).

Coronary arteriography and left ventriculography were performed from the femoral artery using the Seldinger technique.

Following the diagnostic procedure a No. 7 Desilets-Hoffman cannula was placed in the femoral artery for systemic arterial pressure measurement and arterial blood sampling. A Cournand catheter was advanced to the pulmonary artery from the femoral vein. A Ganz coronary sinus thermodilution catheter was advanced to the coronary sinus from a left antecubital vein. Lead II of the electrocardiogram was recorded. Systemic, pulmonary artery, and coronary sinus pressures were measured using Bell and Howell transducers, and were recorded by a Mingograf 82 recorder. 
Table 1 Coronary arteriographic findings

\begin{tabular}{lll}
\hline Case no. & Age and sex & Coronary arteriogram \\
\hline Group 1 & & \\
1 & $39 \mathrm{~F}$ & Normal \\
2 & $54 \mathrm{M}$ & Normal \\
3 & $61 \mathrm{M}$ & 3-vessel disease \\
4 & $63 \mathrm{M}$ & 3-vessel disease \\
5 & $61 \mathrm{M}$ & 2-vessel disease \\
Group 2 & & \\
6 & $48 \mathrm{M}$ & 3-vessel disease \\
7 & $48 \mathrm{M}$ & 2-vessel disease \\
8 & $58 \mathrm{M}$ & 3-vessel disease \\
9 & $60 \mathrm{M}$ & 3-vessel disease \\
10 & $53 \mathrm{M}$ & 1-vessel disease \\
\hline
\end{tabular}

Group 1-heart rate free.

Group 2-heart rate fixed.

Coronary sinus flow, which has been shown to represent nearly all of the left ventricular myocardial blood flow (Hood, 1968), was determined using the continuous thermodilution technique of Ganz et al. (1971). These authors showed close agreement between this and other methods of measuring myocardial blood flow (Ganz et al., 1971). In an attempt to include the contribution to coronary sinus flow of the posterior interventricular vein, close approximation of the downstream thermistor to the orifice of the coronary sinus was ensured by injection of contrast medium before each flow estimation.

Arterial and coronary sinus oxygen contents were measured by the fuel-cell technique (Lex $\mathrm{O}_{2}$ Con) which has been found to give results in close agreement with those obtained using the manometric technique of Van Slyke (Adams and Cole, 1975).

Cardiac output was measured by the indocyanine green dye dilution technique, the dye being injected into the pulmonary artery and sampled from the femoral artery.

After at least 40 minutes had elapsed from the time of injection of contrast medium, control recordings of heart rate, systemic and pulmonary arterial pressures, and coronary sinus pressure were made together with determinations of cardiac output and coronary sinus flow.

Simultaneous arterial and coronary sinus blood samples were withdrawn for oxygen content estimations. A solution of sodium nitroprusside $(100 \mu \mathrm{g} / \mathrm{ml}$ $5 \%$ dextrose) was infused using an IVAC controlled infusion pump until a fall in mean systemic arterial pressure of between 5 and $15 \mathrm{mmHg}$ was achieved. Measurements were then repeated. Phenylephrine $(4 \mu \mathrm{g} / \mathrm{ml} 5 \%$ dextrose) was then infused using a Harvard pump at a rate sufficient to raise mean arterial pressure as closely as possible to control level.
To eliminate the effects of changes in heart rate a group of 5 patients whose heart rate was fixed by atrial pacing at 20 beats/minute above the sinus rate was studied (group 2). The results from this group were compared with those from 5 patients in sinus rhythm (group 1). The patients in each group were randomly selected.

\section{CALCULATIONS}

Mean systemic arterial pressure (MAP), mean pulmonary arterial pressure (MPA), and mean coronary sinus pressure (MCSP $=$ mean right atrial pressure) were obtained by electronic integration of the phasic pressures. Pulmonary artery enddiastolic pressure (PADP) was taken to represent left ventricular filling pressure (Bouchard et al., 1971).

Cardiac index (CI) $\left(1 /\right.$ min per $\left.\mathrm{m}^{2}\right)=$ cardiac output (CO)/body surface area.

Stroke volume index $\left(\mathrm{ml}\right.$ per $\left.\mathrm{m}^{2}\right)=$ stroke volume/ body surface area.

Systemic vascular resistance (dynes $\mathrm{s} \mathrm{cm}^{-5}$ ) $=80 \times$ (MAP - MCSP)/CO.

Pulmonary vascular resistance (dynes $\mathrm{s} \mathrm{cm}^{-5}$ ) $=$ $80 \times($ MPA - PADP $) / C O$.

Coronary vascular resistance (dynes $\mathrm{s} \mathrm{cm}^{-5}$ ) = $80000 \times(\mathrm{MAP}-\mathrm{MCSP}) / \mathrm{CSF}$ where $\mathrm{CSF}=$ coronary sinus flow ( $\mathrm{ml} / \mathrm{min})$.

Myocardial oxygen consumption $(\mathrm{ml} / \mathrm{min})=\mathrm{CSF}$ $\times \mathrm{AVO}_{2}$ difference where $\mathrm{AV} \mathrm{O} \mathrm{O}_{2}$ difference $(\mathrm{ml} / 100 \mathrm{ml})=$ coronary arteriovenous oxygen difference.

Myocardial oxygen extraction (\%) $=100 \times \mathrm{AV} \mathrm{O}_{2}$ difference/arterial $\mathrm{O}_{2}$ content.

Left ventricular stroke work index $\left(\mathrm{g} \mathrm{m}^{\mathrm{m}}\right.$ per $\left.\mathrm{m}^{2}\right)=$ (MAP - PADP) $\times$ SVI $\times 0.0136$

Statistical analysis was by the paired Student's $t$ test.

\section{Results}

CINEANGIOCARDIOGRAPHIC FINDINGS

Left ventricular ejection fraction was normal in all patients. Coronary arteriography demonstrated greater than 50 per cent stenosis of one or more of the major coronary arterial branches in eight patients. In two patients the coronary arteries were normal (Table 1).

\section{EFFECTS ON SYSTEMIC HAEMODYNAMICS}

(Table 2)

\section{Group 1}

The mean fall in mean arterial pressure after nitroprusside infusion was $9 \mathrm{mmHg}$. There was an associated rise in heart rate in all patients (mean 23 beats/minute). A fall in left ventricular filling 
Table 2 Systemic haemodynamic effects of nitroprusside and phenylephrine

\begin{tabular}{|c|c|c|c|c|c|c|c|c|c|c|c|c|c|c|c|c|c|c|c|c|c|c|c|c|c|}
\hline \multirow[t]{2}{*}{ Case no. } & \multicolumn{3}{|c|}{$\begin{array}{l}H R \\
\text { (beats/min) }\end{array}$} & \multicolumn{3}{|c|}{$\begin{array}{l}M A P \\
(m m H g)\end{array}$} & \multicolumn{3}{|c|}{$\begin{array}{l}C I \\
\left(I / \min \text { per } m^{2}\right)\end{array}$} & \multicolumn{3}{|c|}{$\begin{array}{l}S V I \\
\left(m l \text { per } m^{2}\right)\end{array}$} & \multicolumn{3}{|c|}{$\begin{array}{l}P A D P \\
(m m H g)\end{array}$} & \multicolumn{3}{|c|}{$\begin{array}{l}\text { LVSWI } \\
\left(\mathrm{g} m \text { per } m^{2}\right)\end{array}$} & \multicolumn{3}{|c|}{$\begin{array}{l}\text { SVR } \\
\left(\text { dynes } \mathrm{scm}^{-5}\right)\end{array}$} & \multicolumn{4}{|c|}{$\begin{array}{l}P V R \\
\left(\text { dynes s } \mathrm{cm}^{-5}\right)\end{array}$} \\
\hline & $C$ & $N \quad N$ & $N+P C$ & $C$ & $N$ & $N+P$ & $C$ & $N$ & $N+P$ & $C$ & $N \quad \Lambda$ & $N+P$ & $C$ & $N \quad 1$ & $N+P$ & $C$ & $N \quad N$ & $N+P C$ & $C$ & $N \quad I$ & $N+P$ & $C$ & $N$ & $N+1$ & P. \\
\hline \multicolumn{26}{|l|}{ Group 1} \\
\hline & 100 & 150 & 88 & 88 & 73 & 85 & $5 \cdot 5$ & $4 \cdot 2$ & $4 \cdot 8$ & 55 & 28 & 55 & 12 & 8 & 10 & 57 & 25 & 56 & 840 & 923 & 3926 & 20 & 52 & 23 & \\
\hline 2 & 70 & 80 & 721 & 108 & 92 & 110 & $4 \cdot 1$ & 3.8 & 3.8 & 58 & 48 & 53 & 12 & 10 & 14 & 76 & 54 & 69 & 1171 & 1090 & 1285 & 45 & 24 & 24 & 8 \\
\hline 3 & 88 & 105 & 57 & 90 & 85 & 98 & 3.8 & 2.9 & $2 \cdot 9$ & 44 & 28 & 51 & 10 & 8 & 12 & 48 & 29 & 55 & 1003 & 1243 & 1462 & 22 & 29 & 89 & + \\
\hline 4 & 75 & 95 & 60 & 86 & 80 & 100 & $4 \cdot 1$ & 3.8 & - & 55 & 38 & - & 12 & 8 & 18 & 56 & 37 & - & 790 & 856 & $5-$ & 30 & 45 & - & \\
\hline 5 & 60 & 80 & 53 & 94 & 92 & 100 & $2 \cdot 3$ & 1.9 & 2.5 & 39 & 24 & 48 & 12 & 8 & 10 & 43 & 27 & 55 & 1437 & 1760 & 1358 & 33 & 80 & 91 & \\
\hline Mean & 79 & 102 & 66 & 93 & 84 & 99 & $4 \cdot 0$ & 3.3 & 3.5 & 50 & 33 & 52 & 12 & 8 & 13 & 56 & 34 & 59 & 1048 & 1174 & 1258 & 30 & 46 & 57 & $\vec{\omega}$ \\
\hline \pm SEM & $7 \cdot 0$ & 12.9 & 96.3 & 3.9 & 93.6 & 4.0 & 00.5 & 0.4 & 0.5 & 3.7 & $\begin{array}{c}4.4 \\
\end{array}$ & 1.5 & 0.4 & 0.4 & 1.5 & $5 \cdot 6$ & $5 \cdot 3$ & 3.4 & 118 & 161 & 116 & 4.5 & 9.9 & $19 \cdot 2$ & g \\
\hline $\mathbf{P}$ & & $=0$ & $<0.02$ & & 0.05 & $<0.00$ & & $<0.025$ & 5 NS & & .005 & 0.02 & & 005 & $<0.05$ & & 0.001 & $1<$ & & NS & NS & & NS & NS & to \\
\hline \multicolumn{26}{|l|}{ Group 2} \\
\hline $\begin{array}{l}6 \\
7\end{array}$ & $\begin{array}{r}95 \\
110\end{array}$ & $\begin{array}{r}95 \\
110\end{array}$ & $\begin{array}{r}95 \\
110\end{array}$ & $\begin{array}{l}90 \\
90\end{array}$ & $\begin{array}{l}84 \\
85\end{array}$ & $\begin{array}{l}98 \\
94\end{array}$ & $\begin{array}{l}5 \cdot 6 \\
5 \cdot 4\end{array}$ & $\begin{array}{l}4 \cdot 8 \\
4 \cdot 3\end{array}$ & $\begin{array}{l}4.8 \\
4.9\end{array}$ & $\begin{array}{l}59 \\
49\end{array}$ & $\begin{array}{l}50 \\
39\end{array}$ & $\begin{array}{l}50 \\
45\end{array}$ & $\begin{array}{l}11 \\
10\end{array}$ & $\begin{array}{l}8 \\
6\end{array}$ & $\begin{array}{l}10 \\
16\end{array}$ & $\begin{array}{l}63 \\
53\end{array}$ & $\begin{array}{l}52 \\
42\end{array}$ & $\begin{array}{l}60 \\
48\end{array}$ & $\begin{array}{l}611 \\
726\end{array}$ & $\begin{array}{l}676 \\
861\end{array}$ & $\begin{array}{l}783 \\
836\end{array}$ & $\begin{array}{l}14 \\
16\end{array}$ & $\begin{array}{l}16 \\
20\end{array}$ & $\begin{array}{l}16 \\
36\end{array}$ & \\
\hline 8 & 90 & 90 & 90 & 86 & 70 & 105 & $2 \cdot 6$ & $2 \cdot 1$ & $3 \cdot 1$ & 29 & 23 & 35 & 8 & 6 & 10 & 30 & 20 & 45 & 1527 & 1577 & 1584 & 73 & 45 & 45 & \\
\hline 9 & 90 & 90 & 901 & 102 & 90 & 110 & $2 \cdot 4$ & $2 \cdot 2$ & $2 \cdot 4$ & 27 & 24 & 27 & 16 & 12 & 16 & 32 & 25 & 34 & 1745 & 1723 & 31890 & 73 & 61 & 73 & \\
\hline 10 & 85 & 85 & 85 & 92 & 76 & 96 & 2.9 & 2.4 & $2 \cdot 6$ & 34 & 28 & 31 & 12 & 10 & 12 & 37 & 25 & 35 & 1283 & 1309 & 1502 & 60 & 36 & 49 & \\
\hline Mean & 94 & 94 & 94 & 92 & 81 & 101 & 3.8 & 3.2 & 3.6 & 40 & 33 & 38 & 11 & 8 & 13 & 43 & 33 & 44 & 1178 & 1229 & 1319 & 47 & 40 & $\mathbf{4 4}$ & \\
\hline$\underset{\mathbf{P}}{ \pm \mathbf{S E M}}$ & & & & & $\begin{array}{l}7 \quad 3.5 \\
<0.01\end{array}$ & $\begin{array}{r}3.0 \\
<0.01\end{array}$ & $\begin{array}{l}00 \cdot 7 \\
1\end{array}$ & $\begin{array}{c}0.6 \\
<0.01\end{array}$ & $\begin{array}{l}0.5 \\
\text { NS }\end{array}$ & $6 \cdot 2$ & $\begin{array}{c}5.1 \\
<0.005\end{array}$ & $\begin{array}{l}4.3 \\
5 \mathrm{NS}\end{array}$ & $1 \cdot 3$ & $\begin{array}{r}1.2 \\
<0.005\end{array}$ & $\begin{array}{c}1.4 \\
5<0.05\end{array}$ & $5^{6 \cdot 4}$ & $\begin{array}{c}6.0 \\
<0.001\end{array}$ & $\begin{array}{c}4.8 \\
1<0.02\end{array}$ & $2^{221}$ & $\begin{array}{l}202 \\
\text { NS }\end{array}$ & $\begin{array}{l}218 \\
\text { NS }\end{array}$ & $13 \cdot 3$ & $\begin{array}{c}7 \cdot 3 \\
\text { NS }\end{array}$ & $\begin{array}{r}9 \cdot 3 \\
\text { NS }\end{array}$ & $>$ \\
\hline
\end{tabular}

HR, heart rate; MAP, mean arterial pressure; CI, cardiac index; SVI, stroke volume index; PADP, pulmonary artery end-diastolic pressure; LVSWI, lefi ventricular stroke work index; SVR, systemic vascular resistance; PVR, pulmonary vascular resistance; SEM, standard error of mean; C, control; N, nitro 6 prusside; $N+P$, nitroprusside + phenylephrine; $P$, significance (significance for $N+P$ refers to change from $N$ ).

pressure (mean $4 \mathrm{mmHg}$ ) was accompanied by significant falls in cardiac index (mean $0.71 / \mathrm{min}$ per $\mathrm{m}^{2}$ ), stroke volume index (mean $17 \mathrm{ml}$ per $\mathrm{m}^{2}$ ), and left ventricular stroke work index (mean $22 \mathrm{~g} \mathrm{~m}$ per $\mathrm{m}^{2}$ ). There was a variable effect on systemic and pulmonary vascular resistance with no significant change in mean values.

The restoration of mean arterial pressure by phenylephrine was associated with falls in heart rate to or below control levels (Fig. 1). In 3 patients there was a bradycardia of 60 beats/minute or below after phenylephrine infusion. Left ventricular filling pressure, stroke volume index, and left ventricular

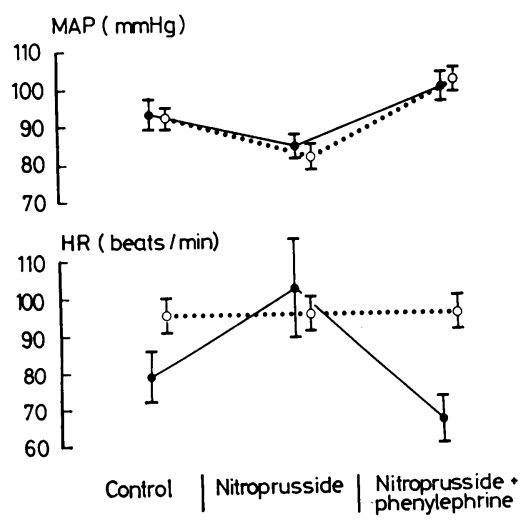

Fig. 1 Effect of nitroprusside and nitroprusside plus phenylephrine on mean arterial pressure $(M A P)$ and heart rate $(H R)$. Closed circles, continuous line-heart rate free; open circles, broken line-heart rate fixed. stroke work index were restored to control levels. Cardiac index was not fully restored in 3 of the 4 patients in whom technically satisfactory cardiac outputs were obtained, reflecting a failure of stroke volume to increase sufficiently to compensate for the relative bradycardia.

\section{Group 2}

Nitroprusside produced a mean fall in mean arterial pressure of $11 \mathrm{mmHg}$. Left ventricular filling pressure fell (mean $3 \mathrm{mmHg}$ ) together with cardiac index (mean $0.6 \mathrm{l} / \mathrm{min}$ per $\mathrm{m}^{2}$ ) and left ventricular stroke work index $\left(10 \mathrm{~g} \mathrm{~m}\right.$ per $\left.\mathrm{m}^{2}\right)$. Stroke volume index fell (mean $7 \mathrm{ml}$ per $\mathrm{m}^{2}$ ), though to a lesser degree than in group 1 in the absence of tachycardia.

Changes in mean systemic and pulmonary vascular resistance were not significant.

There was a tendency for phenylephrine to reverse the haemodynamic changes induced by nitroprusside.

Changes in mean values for cardiac index, stroke volume index, pulmonary arterial end-diastolic pressure, and left ventricular stroke work index for the two groups are illustrated in Fig. 2.

\section{EFFECTS ON CORONARY DYNAMICS (Table 3)}

\section{Group 1}

Nitroprusside increased coronary sinus flow in all patients (mean $19 \mathrm{ml} / \mathrm{min}$ ). This was associated with highly significant falls in mean coronary $\mathrm{AV} \mathrm{O}_{2}$ difference and myocardial oxygen extraction. There was no significant change in mean myocardial 


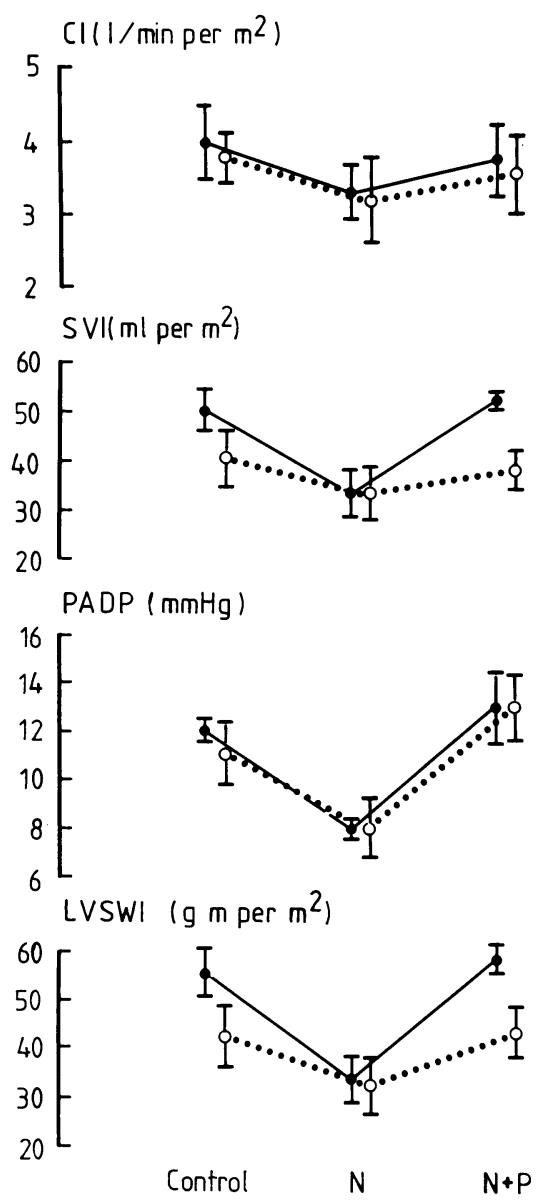

Fig. 2 Effect of nitroprusside and nitroprusside plus phenylephrine on cardiac index $(C I)$, stroke volume index (SVI), pulmonary artery end-diastolic pressure $(P A D P)$, and left ventricular stroke work index (LVSWI). Closed circles, continuous line-heart rate free; open circles, broken line-heart rate fixed. $N=$ nitroprusside, $N+P=$ nitroprusside plus phenylephrine.

oxygen consumption. Mean coronary vascular resistance fell significantly.

Phenylephrine further increased coronary sinus flow in 3 patients. Slight reductions in flow occurred in 2 . However, in 4 patients the reduction in coronary $\mathrm{AV} \mathrm{O}_{2}$ difference and myocardial oxygen extraction was maintained or increased (Fig. 3). There was no significant change in mean myocardial oxygen consumption during phenylephrine infusion. There were variable individual changes in coronary vascular resistance with no change in the mean.

Group 2

In contrast to group 1, nitroprusside consistently produced falls in coronary sinus flow with no significant changes in coronary $\mathrm{AV} \mathrm{O}_{2}$ difference or myocardial oxygen extraction. Hence there was a uniform fall in myocardial oxygen consumption. Mean coronary vascular resistance increased significantly.

The effects of phenylephrine differed from those found in group 1. There was a uniform rise in coronary sinus flow which was not accompanied by significant changes in coronary $\mathrm{AV} \mathrm{O}_{2}$ differences or myocardial oxygen extraction in 4 patients, though there was a fall in the latter in one (Fig. 3). Myocardial oxygen consumption increased in all patients. Changes in myocardial oxygen consumption for individual patients are compared with group 1 in Fig. 4. Coronary vascular resistance fell in 4 patients and increased in 1.

\section{Discussion}

In this study where nitroprusside was given to patients with normal left ventricular function there were falls in left ventricular filling pressure and systemic arterial pressure resulting in falls in cardiac output and left ventricular stroke work. In patients in sinus rhythm there was a conspicuous reflex tachycardia. These changes contrast with those observed in patients with left ventricular failure where cardiac index and left ventricular stroke work improve (Chatterjee et al., 1973).

In patients in group 1 , these haemodynamic changes produced no significant change in myocardial oxygen consumption, suggesting that changes in its determinants occurred in such a way that their influences on this variable counteracted each other. Under the circumstances nitroprusside increased coronary sinus flow, and reduced coronary vascular resistance and myocardial oxygen extraction.

In contrast, in group 2 where changes in heart rate were artificially eliminated by atrial pacing nitroprusside decreased myocardial oxygen consumption. ${ }^{1}$ The decrease in myocardial oxygen

${ }^{1}$ The control mean value for myocardial oxygen consumption in this group was slightly lower than that of group 1 (Table 3 ). This is unexpected since the higher heart rate in group 2 should have given a higher value for myocardial oxygen consumption. A possible explanation is that the low values for coronary sinus flow obtained for 2 patients in this group (cases 7 and 8 ) represented great cardiac vein flow if the posterior interventricular vein joined the coronary sinus nearer its orifice than usual so that the proximal thermistor of the catheter was situated upstream to the posterior interventricular vein. The values for myocardial oxygen consumption in these patients would, therefore, represent a smaller fraction of total myocardial oxygen consumption than in the remaining patients in this group. It is, however, reasonable to assume that changes in this fraction were representative of changes in total myocardial oxygen consumption. 
Table 3 Coronary haemodynamic effects of nitroprusside and phenylephrine

\begin{tabular}{|c|c|c|c|c|c|c|c|c|c|c|c|c|c|c|c|}
\hline & \multicolumn{3}{|c|}{$\begin{array}{l}C S F \\
(m l / m i n)\end{array}$} & \multicolumn{3}{|c|}{$\begin{array}{l}A V O_{2} \text { diff. } \\
(m l / 100 m l)\end{array}$} & \multicolumn{3}{|c|}{$\mathrm{O}_{2} \operatorname{extr}(\%)$} & \multicolumn{3}{|c|}{$\begin{array}{l}M \dot{V} O \\
(m l / m i n)\end{array}$} & \multicolumn{3}{|c|}{$\begin{array}{l}\text { CVR } \\
\left.\text { (dynes s cm-' } \times 10^{-3}\right)\end{array}$} \\
\hline & $C$ & $\boldsymbol{N}$ & $N+P$ & $C$ & $N$ & $N+P$ & $C$ & $N$ & $N+P$ & $C$ & $N$ & $N+P$ & $C$ & $N$ & $N+P$ \\
\hline $\begin{array}{l}\text { Group } 1 \\
1 \\
2 \\
3 \\
4 \\
5 \\
\text { Mean } \\
\pm \text { SEM } \\
\text { P }\end{array}$ & $\begin{array}{r}136 \\
277 \\
142 \\
150 \\
137 \\
168 \\
27\end{array}$ & $\begin{array}{l}146 \\
295 \\
181 \\
173 \\
138 \\
187 \\
28 \\
<0.05\end{array}$ & $\begin{array}{r}150 \\
273 \\
228 \\
150 \\
178 \\
196 \\
24 \\
\text { NS }\end{array}$ & $\begin{array}{r}12.0 \\
13.3 \\
11.5 \\
12.5 \\
13.3 \\
12.5 \\
0.4\end{array}$ & $\begin{array}{c}10.5 \\
10.8 \\
10.1 \\
11.4 \\
12.4 \\
11.0 \\
0.4 \\
<0.01\end{array}$ & $\begin{array}{r}10.9 \\
11.4 \\
9.5 \\
12.8 \\
12.5 \\
11.4 \\
0.6 \\
\text { NS }\end{array}$ & $\begin{array}{c}66 \\
63 \\
62 \\
67 \\
68 \\
65 \\
1 \cdot 2\end{array}$ & $\begin{array}{l}58 \\
53 \\
54 \\
61 \\
64 \\
58 \\
2.0 \\
<0.00\end{array}$ & $\begin{array}{c}60 \\
54 \\
51 \\
68 \\
64 \\
59 \\
3 \cdot 1 \\
1 \mathrm{NS}\end{array}$ & $\begin{array}{c}16 \\
37 \\
16 \\
19 \\
18 \\
21 \\
4.0\end{array}$ & $\begin{array}{l}15 \\
32 \\
18 \\
20 \\
17 \\
20 \\
3 \cdot 0 \\
\text { NS }\end{array}$ & $\begin{array}{c}16 \\
31 \\
22 \\
19 \\
22 \\
22 \\
2 \cdot 5 \\
\text { NS }\end{array}$ & $\begin{array}{c}49 \\
30 \\
50 \\
43 \\
51 \\
45 \\
\mathbf{4} \cdot 0\end{array}$ & $\begin{array}{l}39 \\
24 \\
38 \\
35 \\
51 \\
37 \\
4.3 \\
<0.05\end{array}$ & $\begin{array}{c}43 \\
31 \\
34 \\
51 \\
51 \\
42 \\
4 \cdot 1 \\
\text { NS }\end{array}$ \\
\hline $\begin{array}{l}\text { Group } 2 \\
6 \\
7 \\
8 \\
9 \\
10 \\
\text { Mean } \\
\pm \underset{P}{\text { SEM }}\end{array}$ & $\begin{array}{r}273 \\
85 \\
84 \\
107 \\
220 \\
154 \\
39\end{array}$ & $\begin{array}{r}230 \\
73 \\
63 \\
96 \\
143 \\
121 \\
30 \\
\text { NS }\end{array}$ & $\begin{array}{c}292 \\
121 \\
88 \\
104 \\
262 \\
173 \\
43 \\
<0.05\end{array}$ & $\begin{array}{r}10.9 \\
12.5 \\
13.8 \\
11.2 \\
8.7 \\
11.4 \\
0.8\end{array}$ & $\begin{array}{r}10 \cdot 7 \\
12.5 \\
14 \cdot 5 \\
10 \cdot 8 \\
9 \cdot 7 \\
11 \cdot 6 \\
0.8 \\
\text { NS }\end{array}$ & $\begin{array}{r}10.9 \\
11 \cdot 2 \\
14.7 \\
11.0 \\
9.3 \\
11.4 \\
0.9 \\
\text { NS }\end{array}$ & $\begin{array}{c}59 \\
63 \\
71 \\
61 \\
41 \\
59 \\
5 \cdot 0\end{array}$ & $\begin{array}{l}58 \\
61 \\
75 \\
59 \\
45 \\
60 \\
4 \cdot 8 \\
\text { NS }\end{array}$ & $\begin{array}{c}58 \\
55 \\
76 \\
60 \\
44 \\
59 \\
5 \cdot 1 \\
\text { NS }\end{array}$ & $\begin{array}{c}30 \\
11 \\
12 \\
12 \\
19 \\
17 \\
3 \cdot 6\end{array}$ & $\begin{array}{c}25 \\
9 \\
9 \\
10 \\
14 \\
13 \\
3.0 \\
<0.01\end{array}$ & $\begin{array}{l}32 \\
14 \\
13 \\
11 \\
24 \\
19 \\
4.0 \\
<0.05\end{array}$ & $\begin{array}{l}25 \\
83 \\
80 \\
72 \\
31 \\
58 \\
12.5\end{array}$ & $\begin{array}{l}29 \\
92 \\
87 \\
72 \\
40 \\
64 \\
12 \cdot 6 \\
<0.05\end{array}$ & $\begin{array}{l}26 \\
61 \\
94 \\
64 \\
28 \\
55 \\
12 \cdot 7 \\
\text { NS }\end{array}$ \\
\hline
\end{tabular}

CSF, coronary sinus flow; AV $\mathrm{O}$, diff., coronary arteriovenous oxygen content difference; $\mathrm{O}$, extr, myocardial oxygen extraction; $\mathrm{MV} \dot{\mathrm{O}}_{\mathrm{O}}$ myocardial oxygen consumption; CVR, coronary vascular resistance; SEM, standard error of mean; C, control; N, nitroprusside; $N+P$, nitroprusside + phenylephrine; $P$, significance (significance for $N+P$ refers to change from $N$ ).

consumption in group 2 was accompanied by a fall in coronary sinus flow, and an increase in coronary vascular resistance with no change in myocardial oxygen extraction.
While the systemic haemodynamic effects of phenyleprhine were similar in the two groups, there were differences in its effects on coronary dynamics. In group 1 where there was a fall in heart rate,

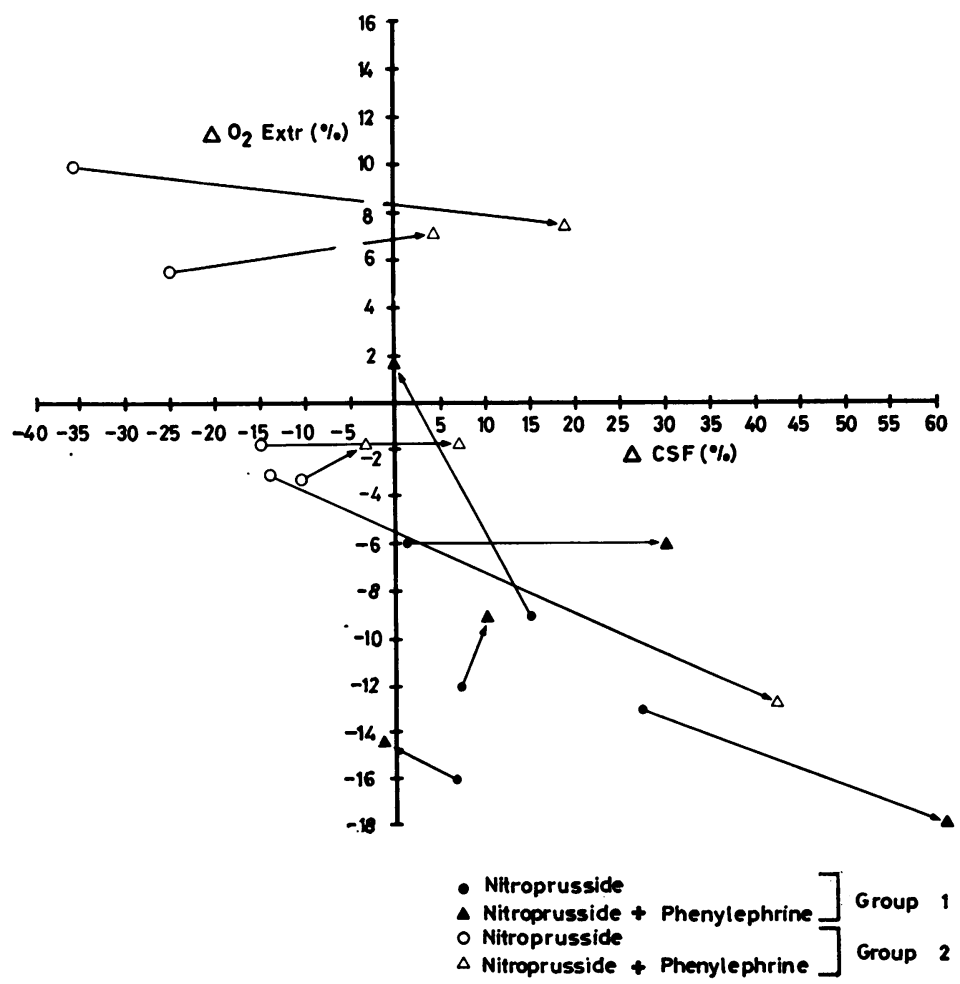

Fig. 3 Effect of nitroprusside and nitroprusside plus phenylephrine on percentage change in myocardial oxygen extraction $\left(\triangle \mathrm{O}_{2}\right.$ extr) and coronary sinus flow $(\triangle C S F)$. Group 1-heart rate free, group 2-heart rate fixed. 


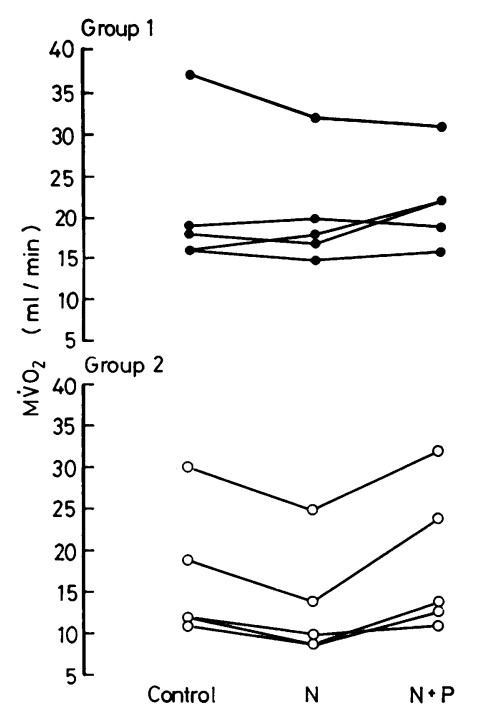

Fig. 4 Effect of nitroprusside and nitroprusside plus phenylephrine on myocardial oxygen consumption $\left(\mathrm{MVO}_{2}\right)$ for individual patients. $N=$ nitroprusside, $N+P=$ nitroprusside plus phenylephrine.

myocardial oxygen consumption was unchanged. The increased perfusion pressure under these circumstances resulted in variable changes in coronary sinus flow, though the decreased myocardial oxygen extraction was in general maintained (Fig. $3)$. In group 2 the increase in systemic arterial pressure by phenylephrine was associated with an increase in myocardial oxygen consumption. Coronary sinus flow increased while myocardial oxygen extraction remained unchanged. Coronary vascular resistance fell in 4 patients.

The interpretation of these observations is complex but it appears that the net effect of nitroprusside on coronary dynamics, at least in patients with normal left ventricular function, depends critically upon prevailing changes in myocardial oxygen consumption. A hypothesis explaining the data may be constructed from evidence obtained from previous studies concerning the control of myocardial blood flow.

In the experimental animal changes in myocardial oxygen demand are met by changes in myocardial blood flow, myocardial oxygen extraction remaining constant (Katz and Feinberg, 1958). That this is true in man is supported by a recent study from this laboratory where changes in myocardial blood flow induced by beta-adrenergic blockade and rapid atrial pacing were associated with a constant myocardial oxygen extraction (Stephens et al., 1978). The relation between myocardial blood flow (oxygen supply) and oxygen demand is maintained primarily by autoregulation, that is a tissue oxygen tension sensitive system involving the release of local metabolites which act to produce changes in coronary vascular tone (Berne, 1964).

This relation may be modified by a vasodilator drug such as nitroprusside which may reduce myocardial oxygen supply relative to demand by reducing coronary perfusion pressure (systemic arterial pressure). Conversely, the myocardial oxygen supply/demand relation may be improved by coronary vasodilatation resulting from a direct action of the drug on the coronary resistance bed. If the latter effect dominated, an improved supply/demand relation would be manifest as an increase in myocardial blood flow, a decrease in myocardial oxygen extraction, or both. Since, however, autoregulation provides a potential coronary vasoconstrictor mechanism, the coronary vasodilator effect of nitroprusside may be prevented if a fall in myocardial oxygen demand initiates a powerful autoregulatory vasoconstrictor response. Similarly, the coronary effects of phenylephrine may not be confined to the increase in coronary perfusion pressure but may encompass complex interactions between changes in myocardial oxygen demand and autoregulation, and the direct effects of nitroprusside and phenylephrine on the coronary arterial vessels.

In the present study it is possible to speculate that in group 1 the effect of the rise in heart rate on myocardial oxygen consumption was balanced by a fall in left ventricular afterload and thus wall tension (Sarnoff et al., 1958; Graham et al., 1968). Under these circumstances there was a primary coronary vasodilator effect of nitroprusside when autoregulation was not initiated. However, in group 2 where there was a fall in myocardial oxygen consumption, autoregulation produced coronary vasoconstriction sufficient to prevent nitroprussideinduced coronary vasodilatation.

These considerations may be extended to provide a possible explanation of the observed effects of the phenylephrine. In group 1 the fall in heart rate balanced the effect of increased afterload on myocardial oxygen consumption so that autoregulation was not initiated. Hence, the coronary vasodilator action of nitroprusside was maintained, though myocardial blood flow was not substantially augmented by the increased coronary perfusion pressure, perhaps because of an opposing coronary vasoconstrictor effect of phenylephrine. In group 2 the net effect of phenylephrine was to produce an increase in myocardial oxygen consumption. Coronary vasodilatation occurred as a result of autoregulation but nitroprusside did not augment this response as shown by the failure of myocardial oxygen extraction to fall. This may have been 
because of an opposing vasoconstrictor action of phenylephrine or more powerful autoregulatory vasodilatation masking that of nitroprusside.

An important assumption in this study is that the presence or absence of coronary artery disease was unimportant with regard to the observed changes in coronary dynamics. Experience in this laboratory has shown that coronary sinus flow accurately represents changes in myocardial blood flow over a wide range of flows in patients with and without coronary artery disease (Stephens et al., 1978). Further, coronary sinus flow increases in an identical linear fashion with incremental increases in heart rate in patients with and without coronary artery disease up to the point of development of angina (Yoshida et al., 1971). It is unlikely, therefore, that the presence of coronary arterial narrowing in the patients in this study influenced the observed changes in myocardial blood flow.

This study provides evidence for a coronary vasodilator effect of nitroprusside in man. However, this action may be prevented by artificially abolishing the associated tachycardia and so reducing myocardial oxygen consumption. The correction of nitroprusside-induced hypotension by phenylephrine does not significantly improve global myocardial oxygenation and may under certain circumstances increase myocardial oxygen consumption.

\section{References}

Adams, L., and Cole, P. (1975). A new method for the direct estimation of blood oxygen content. Cardiovascular Research, 9, 443-446.

Berne, R. M. (1964). Regulation of coronary blood flow. Physiological Reviews, 44, 1-29.

Bouchard, R. J., Gault, J. H., and Ross, J., Jr. (1971). Evaluation of pulmonary arterial end-diastolic pressure as an estimate of left ventricular end-diastolic pressure in patients with normal and abnormal left ventricular performance. Circulation, 44, 1072-1079.

Chatterjee, K., Parmley, W. W., Ganz, W., Forrester, J., Walinsky, P., Crexells, C., and Swan, H. J. C. (1973). Haemodynamic and metabclic responses to vasodilator therapy in acute myocardial infarction. Circulation, 48, $\subseteq$ 1183-1193.

Chiariello, M., Gold, H. K., Leinbach, R. C., Davis, M. A., and Maroko, P. R. (1976). Comparison between the effects of nitroprusside and nitroglycerin on ischemic injury during acute myocardial infarction. Circulation, 54, 766-773.

da Luz, P. L., Forrester, J. S., Wyatt, H. L., Tyberg, J. V., Chagrasulis, R., Parmley, W. W., and Swan, H. J. C. (1975). Haemodynamic and metabolic effects of sodium nitroprusside on the performance and metabolism of regional ischaemic myocardium. Circulation, 52, 400-407.

Franciosa, J. A., Guiha, N. H., Limas, C. J., Rodiguera, E., and Cohn, J. N. (1972). Improved left ventricular function during nitroprusside infusion in acute myocardial infarction. Lancet, 1, 650-654.

Ganz, W., Tamura, K., Marcus, H. S., Donoso, R., Yoshida, S., and Swan, H. J. C. (1971). Measurement of coronary sinus blood flow by continuous thermodilution in man. Circulation, 44, 181-195.

Graham, T. P., Jr., Covell, J. W., Sonnenblick, E. H., Ross, J., Jr., and Braunwald, E. (1968). Control of myocardial oxygen consumption-relative influence of contractile state and tension development. Fournal of Clinical Investigation 47, 375-385.

Hood, W. B., Jr. (1968). Regional venous drainage of the human heart. British Heart fournal, 30, 105-108.

Katz, L. N., and Feinberg, H. (1958). The relation of cardiac effort to myocardial oxygen consumption and coronary flow. Circulation Research, 6, 656-669.

Parmley, W. W., Chatterjee, K., Charuzi, Y., and Swan, H. J. C. (1974). Hemodynamic effects of systolic unloading (nitroprusside) and diastolic augmentation (external counterpulsation) in patients with acute myocardial infarction. American fournal of Cardiology, 33, 819-825.

Sarnoff, S. J., Braunwald, E., Welch, G. H., Case, R. B., Stansby, W. N., and Macruz, R. (1958). Haemodynamic determinants of oxygen consumption of the heart with special reference to the tension-time index. American fournal of Physiology, 192, 148-156.

Stephens, J., Hayward, R., Ead, H., Adams, L., Hamer, J., and Spurrell, R. (1978). Effects of selective and nonselective beta-adrenergic blockade on coronary dynamics in man assessed by rapid atrial pacing. British Heart fournal, 40, 856-863.

Yoshida, S., Ganz, W., Donoso, R., Marcus, H., and Swan, H. J. C. (1971). Coronary hemodynamics during successive elevation of heart rate by pacing in subjects with angina pectoris. Circulation, 44, 1062-1071.

Requests for reprints to Dr J. D. Stephens, Department of Cardiology, St Bartholomew's Hospital, London EC1A 7BE. 